TAM_MS_Revised.docx

\title{
Nonaqueous Electrochemical Oxidation of Tamoxifen
}

\author{
Kan Wu, ${ }^{1}$ Stephen J. Van Wyck, William. E. Geiger ${ }^{*}$ \\ University of Vermont, Department of Chemistry, Burlington, VT 05405, USA
}

\begin{abstract}
The electrochemical oxidation of the chemotherapeutic anti-cancer agent tamoxifen, 1, was studied by voltammetry and electrolysis. Three successive one-electron anodic reactions were observed for 1 in dichloromethane containing weakly-coordinating $\left[\mathrm{B}\left(\mathrm{C}_{6} \mathrm{~F}_{5}\right)_{4}\right]^{-}$as the supporting electrolyte anion. The first (totally irreversible) oxidation ( $c a 0.64 \mathrm{~V} v s$ ferrocene) occurs at the tertiary amine, giving a putative amine radical cation $\mathbf{1}^{+\bullet}$ that abstracts a hydrogen atom, most likely from solvent, to give the corresponding ammonium ion $\mathbf{1}-\mathbf{H}^{+}$. The latter is responsible for the two further one-electron oxidations, which take place at the triarylethynyl part of the molecule $\left(\mathrm{E}_{1 / 2}\right.$ values of $0.94 \mathrm{~V}$ and $1.33 \mathrm{~V} v$ s ferrocene). Bulk oxidation of 1 at $\mathrm{E}_{\mathrm{appl}}=0.6 \mathrm{~V}$ produces the ammonium ion $\mathbf{1}-\mathbf{H}^{+}$, which can be cathodically reduced back to neutral tamoxifen in an overall chemically reversible process. The present findings are not consistent with the mechanism described in previous literature for the anodic oxidation of tamoxifen.
\end{abstract}

E-mail address: william.geiger@uvm.edu (W.E. Geiger)

${ }^{1}$ Present address: Shanghi Institute for Advance Immunochemical Studies, Pudong, Shanghi 201210 China.

Keywords: tamoxifen; electrochemical oxidation; nonaqueous; radical cation; H-atom abstraction; tetrakis(perfluoroaryl)borate anion. 


\section{Introduction}

Tamoxifen, [Z-1-[4-(2-dimethylamino)ethoxy]phenyl-1,2-diphenylbut-1-ene], 1, is a selective estrogen receptor modulator (an "antiestrogen") used in the treatment of human breast cancer $[1,2]$. It is widely accepted that the oxidative metabolism of tamoxifen by cytochrome P450 and other enzymes produces metabolites that may play a role in adverse side effects of the drug [3]. A better understanding of the biomedical outcomes of tamoxifen has been hampered, in part, by the scarcity of information about the redox mechanisms of tamoxifen and its metabolites [3]. Electrochemical methods have often proven worthwhile in modeling metabolic redox reactions [4-6]. However, although voltammetric methods have been described for the electrochemical analysis of tamoxifen down to trace levels [7-9], neither the effects of different electrolyte media on its electrochemical behavior, nor mechanistic aspects of its redox reactions have been well explored. The present paper, which appears to be the first report on the electrochemical oxidation of tamoxifen under nonaqueous conditions, is able to describe the oxidation mechanism of $\mathbf{1}$ under mild electrolyte conditions, and offer comments on previous assignments [7-9] of its oxidation products under protic conditions.

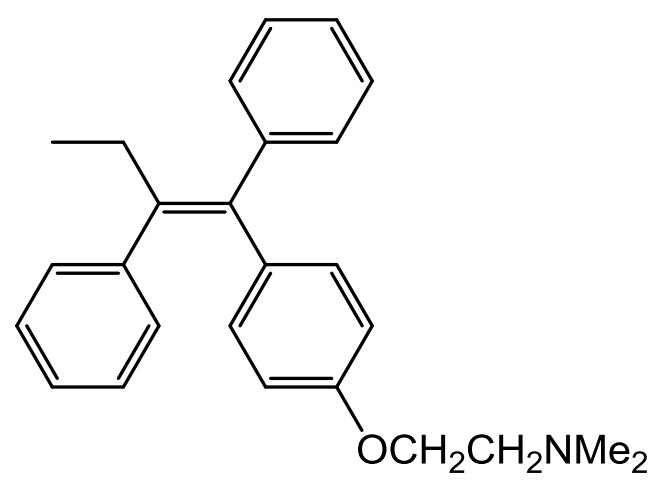

Tamoxifen (1)

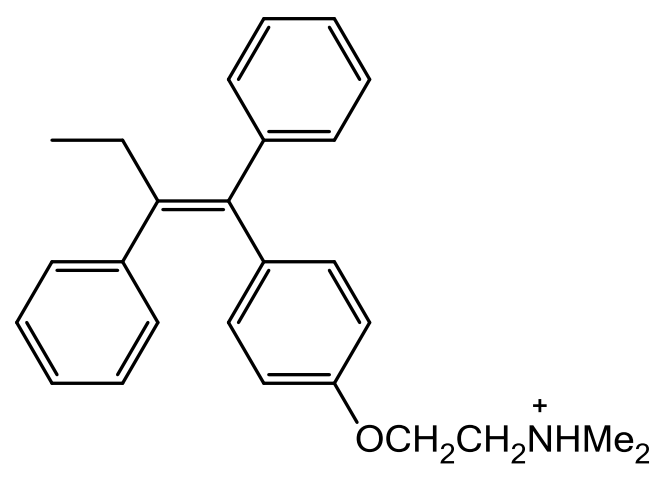

1-H

\section{Experimental}

\subsection{General}

Electrochemical procedures were carried out under nitrogen in a Vacuum Atmospheres drybox. Dichloromethane was purified and dried by passing it through an alumina-based solvent 
system under argon. A previously published procedure [10] was employed for the preparation of $\left[\mathrm{NBu}_{4}\right]\left[\mathrm{B}\left(\mathrm{C}_{6} \mathrm{~F}_{5}\right)_{4}\right]$. Commercial sources were used to obtain tamoxifen (Combi-Blocks, San Diego, $\mathrm{CA}$, used as received) and $\left[\mathrm{NBu}_{4}\right]\left[\mathrm{PF}_{6}\right]$ (Tokyo Chemical Industry). The latter was recrystallized from absolute ethanol and vacuum dried at $373 \mathrm{~K}$. Elemental analyses were performed at Robertson Laboratories.

\subsection{Electrochemistry}

Three-electrode cells were employed for voltammetry and electrolysis experiments. For voltammetry experiments, a platinum wire counter-electrode was either immersed directly in the working compartment or separated from it by a fine frit. For electrolysis experiments, a platinum gauze electrode, separated from the working compartment by a fine glass frit, was employed as a counter-electrode. In both cases, the experimental reference electrode, immersed in an electrolyte solution separated by a fine frit from the working compartment, was a silver wire electroplated with silver chloride. All potentials reported in this paper are referenced to the ferrocene/ferrocenium potential [11], which was checked in each experiment $v s$ the experimental $\mathrm{Ag} / \mathrm{AgCl}$ potential by the ferrocene in situ method [12]. The working electrode for voltammetry was either a $2 \mathrm{~mm}$ gold or platinum electrode or a glassy carbon electrode (GCE) of 1-2 mm diameter, all of which were purchased from Bioanalytical Systems. Before each experiment, and if necessary after each scan, the electrode was buffed with diamond polishing compound, washed with nanopure water, and vacuum dried. The working electrode for bulk electrolysis was a platinum gauze basket that had been stored in nitric acid, washed with nanopure water, and either flame-dried or dried at $393 \mathrm{~K}$ for at least $24 \mathrm{~h}$. The potentiostats employed were EG\&G PARC 273 and 273A models, interfaced to a personal computer. Most CV scans were subtracted for background currents. Although analyte concentrations were usually about $1 \mathrm{mM}$, experiments on other concentrations over the range of $0.45 \mathrm{mM}$ to $8.8 \mathrm{mM}$ were included as will be noted in the text. Electrochemistry was carried out at either $298 \mathrm{~K}$ or ambient temperature.

\section{Results}

\subsection{Voltammetry}

The anodic electrochemistry of a number of multi-aryl ethylenes have been described [13-21]. Both triaryl ethylenes and tetraaryl ethylenes generally undergo two reversible one-electron 
oxidations, often at proximate $\mathrm{E}_{1 / 2}$ potentials [14, 16-18]. None of those systems, however, has a redox-active aryl substituent, as is so with the (dimethylamino)ethoxy group of tamoxifen. As shown below, aryl-ethylene based oxidations are also seen for tamoxifen, but they occur at potentials that are positive of the more facile oxidation of the dimethyamino group. We also note that the supporting electrolyte anion played an important role in giving reproducible voltammetric data. When the electrochemical medium was $\mathrm{CH}_{2} \mathrm{Cl}_{2} / 0.1 \mathrm{M}\left[\mathrm{NBu}_{4}\right]\left[\mathrm{PF}_{6}\right]$, the cyclic voltammetry (CV) scans were irreproducible and gave irregular peak heights, as exemplified by Figure 1. Improved voltammetric behavior was observed in $\mathrm{CH}_{2} \mathrm{Cl}_{2} / 0.05 \mathrm{M}$ $\left[\mathrm{NBu}_{4}\right]\left[\mathrm{B}\left(\mathrm{C}_{6} \mathrm{~F}_{5}\right)_{4}\right]$, which was medium of choice for this study. As previously described [22-26], when compared to the anions traditionally used in nonaqueous solvents (e.g., $\left[\mathrm{ClO}_{4}\right]^{-},\left[\mathrm{BF}_{4}\right]^{-}$, $\left.\left[\mathrm{PF}_{6}\right]^{-}\right),\left[\mathrm{B}\left(\mathrm{C}_{6} \mathrm{~F}_{5}\right)_{4}\right]^{-}$and other weakly-coordinating anions (WCAs) tend to form more soluble salts of positively-charged homogeneous electrolysis products, thereby minimizing electrode adsorption and "blockage" problems. Furthermore, WCAs are inherently less nucleophilic than are the traditional anions, a property that virtually eliminates their reactions with radical cations.

A typical CV scan of tamoxifen in $\mathrm{CH}_{2} \mathrm{Cl}_{2} / 0.05 \mathrm{M}\left[\mathrm{NBu}_{4}\right]\left[\mathrm{B}\left(\mathrm{C}_{6} \mathrm{~F}_{5}\right)_{4}\right]$ is shown in Figure 2. Of the three anodic waves, only the second was chemically reversible under all scan and concentration conditions. The first oxidation wave $\left(\mathrm{E}_{\mathrm{pa}}(1)=0.64 \mathrm{~V}\right.$ at $\left.0.2 \mathrm{~V} \mathrm{~s}^{-1}\right)$ has the shape of a totally irreversible one-electron process [27] $\left(\mathrm{E}_{\mathrm{p}}-\mathrm{E}_{\mathrm{p} / 2}=91 \mathrm{mV}, \beta=0.52\right)$, which is characteristic of the oxidation of an aliphatic amine [28-30]. Furthermore, its potential fits well with those of simple tertiary amines (e.g. $\mathrm{E}_{\mathrm{pa}} \mathrm{ca} 0.64 \mathrm{~V}$ for $\mathrm{NEt}_{3}, 0.74 \mathrm{~V}$ for $\mathrm{NMe}_{3}[29,31]$ ). The second oxidation wave $\left(\mathrm{E}_{1 / 2}(2)=0.94 \mathrm{~V}\right)$ has the characteristics of a one-electron reversible system $\left(E_{p}-E_{p / 2}=60 \mathrm{mV}, E_{p a}-E_{p c}=80 \mathrm{mV}\right.$, typical of what we measure for a quasi-Nernstian process under these conditions). Regarding the third wave, the fact that chemical reversibility was observed under some conditions [32] allowed us to assign a value of $\mathrm{E}_{1 / 2}(3)=1.33 \mathrm{~V}$ to this reaction.

Square-wave voltammetry (SWV) (see Figure 3) confirmed that the second oxidation was the only quasi-Nernstian process among the three processes, based on the markedly greater current for the second wave [33].

As will be shown below, the follow-up product of the first (amine-based) oxidation of tamoxifen is the simple tertiary ammonium compound $\mathbf{1 - \mathbf { H } ^ { + }}$, formed apparently when the 
putative radical cation $\mathbf{1}^{+\bullet}$ abstracts hydrogen very quickly from an $\mathrm{H}$-atom donor (most likely the solvent). Taken together, the voltammetry and electrolysis experiments are consistent with the reaction sequence of Eqs 1-3 to account for the anodic behavior of tamoxifen under these conditions. Whereas the potentials in Eqs 2 and 3 are $E_{1 / 2}$ values, the potential of $0.64 \mathrm{~V}$ given in $\mathrm{Eq} 1$ is an $\mathrm{E}_{\mathrm{pa}}$ value (scan rate $0.2 \mathrm{~V} \mathrm{~s}^{-1}$ ), which is likely to be somewhat negative of $\mathrm{E}_{1 / 2}(1)$ owing to the effect of the fast follow-up reaction of $\mathbf{1}^{+}[34,35]$.

$$
\begin{aligned}
& \mathbf{1}-\mathrm{e}^{-} \stackrel{0.64 \mathrm{~V}}{\rightleftharpoons} \mathbf{1}^{+\cdot} \stackrel{\text { solvent-H }}{\longrightarrow} \mathbf{1 - H ^ { + }} \\
& \mathbf{1}-\mathbf{H}^{+}-\mathrm{e}^{-} \stackrel{0.94 \mathrm{~V}}{\rightleftharpoons} \mathbf{1}-\mathbf{H}^{2+} \\
& \mathbf{1 - H ^ { 2 + }}-\mathrm{e}^{-} \stackrel{1.33 \mathrm{~V}}{\rightleftharpoons} \mathbf{1}-\mathbf{H}^{3+} \longrightarrow \text { unknown product }
\end{aligned}
$$

\subsection{Electrolysis}

Bulk anodic electrolyses carried out on 1 at applied potentials of 0.6 to $0.7 \mathrm{~V}$ were sufficient to complete the first oxidation of tamoxifen. Analyte concentrations of 3 to $8.8 \mathrm{mM} \mathbf{1}$ in $\mathrm{CH}_{2} \mathrm{Cl}_{2} / 0.05 \mathrm{M}\left[\mathrm{NBu}_{4}\right]\left[\mathrm{B}\left(\mathrm{C}_{6} \mathrm{~F}_{5}\right)_{4}\right]$ consistently passed $1.0 \mathrm{~F}$, confirming the one-electron stoichiometry of Eq 1 [36]. CV scans of the electrolyzed solution in the positive potential range (solid line in Figure 4) showed the disappearance of the first anodic wave of $\mathbf{1}$, but the retention of the original second and third waves. This established that the dominant follow-up product for the one-electron oxidation of $\mathbf{1}$ retains its triarylethynyl structure and is the same on the CV and bulk electrolysis time scales.

Among the methods used to characterize the electrolysis product $\mathbf{1}-\mathbf{H}^{+}$were $\mathrm{CV}$ scans of the bulk electrolysis solutions in the negative potential region. An irreversible cathodic wave was observed for the product at $\mathrm{E}_{\mathrm{pc}}=-1.3 \mathrm{~V}$ to $-1.5 \mathrm{~V}$, depending on the nature of the working electrode [37] (Figure 5). Exhaustive re-electrolysis negative of this potential again passed about $1 \mathrm{~F}$ of charge and re-produced the original three anodic peaks of $\mathbf{1}$ in about $85 \%$ yield (see circular points in Figure 4). Equation 4 describes the overall chemically reversible process in which $\mathbf{1}$ is re-formed by reduction of the initial oxidation product $\mathbf{1}-\mathbf{H}^{+}$. 


$$
\mathbf{1} \underset{-\mathrm{e}^{-}}{\rightleftharpoons} \mathbf{1}^{+\cdot} \stackrel{\text { solvent-H}}{\longrightarrow} \mathbf{1 - \mathbf { H } ^ { + }} \underset{+\mathrm{e}^{-}}{\stackrel{c a-1.5 \mathrm{~V}}{\longrightarrow} \mathbf{1}}+\mathrm{H}^{\bullet}
$$

A work-up of the original anodic electrolysis solution was carried out to aid in the identification of the one-electron product. After removal of the solvent from the electrolysis solution, the remaining solid was re-dissolved in a minimum amount of dichloromethane and placed on a silica gel column. After elution with dichloromethane removed the $\left[\mathrm{NBu}_{4}\right]\left[\mathrm{B}\left(\mathrm{C}_{6} \mathrm{~F}_{5}\right)_{4}\right]$ supporting electrolyte, a 1:9 methanol:dichloromethane mixture was used to obtain the product, which eluted as a yellow band, giving about a 50\% yield of the primary oxidation product [1$\mathbf{H}]\left[\mathrm{B}\left(\mathrm{C}_{6} \mathrm{~F}_{5}\right)_{4}\right]$ [38]. CV scans of the isolated product reproduced both the two anodic waves of 1$\mathbf{H}^{+}$at $0.94 \mathrm{~V}$ and $1.33 \mathrm{~V}$ (Eqs 2 and 3, respectively) and the cathodic wave for $\mathbf{1 - \mathbf { H } ^ { + }}$ at $c a-1.5 \mathrm{~V}$. The CVs of the isolated product always showed a small pre-wave at the potential of $0.6 \mathrm{~V}$ owing to the presence of about $10-15 \%$ of $\mathbf{1}$. It is likely that some deprotonation of $\mathbf{1 - \mathbf { H } ^ { + }}$ occurs during the product workup.

Protonation of the amine in $\mathbf{1 - \mathbf { H } ^ { + }}$ was verified by its ${ }^{1} \mathrm{H}$ NMR spectrum, in which major downfield shifts were observed for the methyl and ethynyl protons on the amino side chain: $\mathrm{CH}_{2}-\mathrm{N}-\left(\mathrm{CH}_{3}\right)_{2}, 0.45 \mathrm{ppm} ;-\underline{\mathrm{CH}}_{2}-\mathrm{N}-\left(\mathrm{CH}_{3}\right)_{2}, 0.55 \mathrm{ppm}$ [39]. The isolated sample exhibited a solution conductance in acetonitrile that was consistent with a 1:1 $\left[\mathrm{B}\left(\mathrm{C}_{6} \mathrm{~F}_{5}\right)_{4}\right]$ salt [40] and gave an elemental analysis consistent with a sample of $[\mathbf{1 - H}]\left[\mathrm{B}\left(\mathrm{C}_{6} \mathrm{~F}_{5}\right)_{4}\right]$ contaminated by a small amount of neutral $\mathbf{1}$ [41]. Finally, when the isolated sample of $[\mathbf{1 - H}]\left[\mathrm{B}\left(\mathrm{C}_{6} \mathrm{~F}_{5}\right)_{4}\right]$ was dissolved in $\mathrm{CH}_{2} \mathrm{Cl}_{2}$ and cathodically reduced, it regenerated neutral $\mathbf{1}$.

\section{Discussion}

The primary finding of this study is that the most facile oxidation of tamoxifen occurs in a one-electron process at its pendant tertiary amine. Under the nonaqueous conditions employed, the very short-lived tamoxifen radical cation, $\mathbf{1}^{+\bullet}$, acts as an $\mathrm{H}$-atom acceptor from solvent or an adventitious reactant, forming the corresponding tertiary ammonium ion $\mathbf{1 - \mathbf { H } ^ { + }}$. Further oxidations of $\mathbf{1 - \mathbf { H } ^ { + }}$ at more positive potentials occur at the arylethynyl part of the molecule.

That the primary redox reaction of 1 follows the overall chemically reversible process of Eq 4 is surprising, given that, to the best of our knowledge, the oxidations of aliphatic amines are not known to follow such a pathway. Rather, electrogenerated radical cations of tertiary amines 
generally experience rapid loss of proton, giving a neutral carbo-radical that either undergoes C$\mathrm{C}$ coupling reactions or a further loss of electrons that gives rise to C-N bond cleavage [28-30, $42,43]$. Certainly, the present nonaqueous conditions differ from those described in the previous literature both in terms of the solvent (dichloromethane $v s$ acetonitrile or DMF) and the nucleophilicity [44] of the supporting electrolyte anion $\left(\left[\mathrm{B}\left(\mathrm{C}_{6} \mathrm{~F}_{5}\right)_{4}\right]^{-}\right.$vs $\left[\mathrm{PF}_{6}\right]^{-},\left[\mathrm{BF}_{4}\right]^{-}$, or $\left.\left[\mathrm{ClO}_{4}\right]^{-}\right)$. The question of whether or not the electrolyte medium is playing a decisive role in the oxidation mechanism of aliphatic amines should be addressed by more systematic studies.

Finally, we wish to comment on what we believe to be an erroneous mechanism previously attributed to the oxidation of tamoxifen. Several papers have described the oxidation of tamoxifen as a two-electron process involving loss of two aryl protons and formation of the diphenyl phenanthrene derivative 2 [3, 7-9]. The basis of this assignment can be traced back to

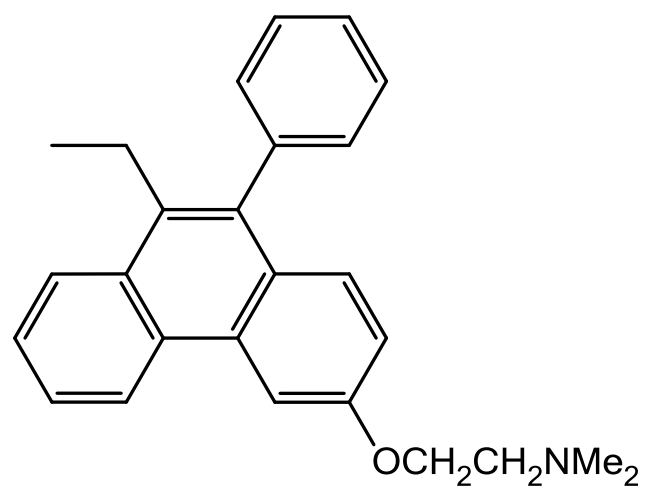

2

an earlier description of the electrochemical oxidation of tetraphenylethylene (3). In that work, Stuart and Ohnesorge isolated 9,10-diphenylphenanthrene (4) after the two-electron anodic oxidation of $\mathbf{3}$ in acetonitrile/[ $\left.\mathrm{NEt}_{4}\right]\left[\mathrm{ClO}_{4}\right][15,45]$. However, it is unlikely that a similar aryl-aryl coupling reaction would accompany the oxidation of tamoxifen, since the more facile oxidation of this compound occurs at the amine rather than at the arylethenyl moiety. The present study does not directly address the mechanism of tamoxifen oxidation under aqueous conditions, which is more immediately relevant to the biological activity of this molecule. However, it does suggest that the aqueous oxidation products of tamoxifen will be more typical of the those of amines, rather than of multiarylethenyl moieties. A re-examination of the oxidation mechanism under aqueous conditions, such as those employed for the electroanalytical determination of tamoxifen [8,9], would be welcome. 


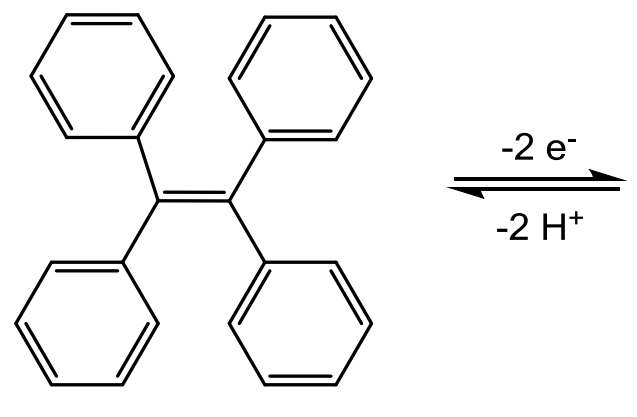

3

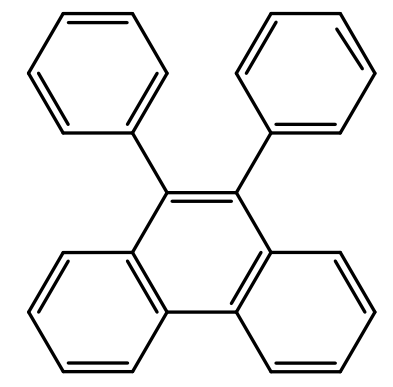

4

\section{Summary}

The anodic electrochemistry of tamoxifen, 1, has been investigated in a nonaqueous electrolyte, $\mathrm{CH}_{2} \mathrm{Cl}_{2} / 0.05 \mathrm{M}\left[\mathrm{NBu}_{4}\right]\left[\mathrm{B}\left(\mathrm{C}_{6} \mathrm{~F}_{5}\right)_{4}\right]$. Cyclic voltammetry and square wave voltammetry experiments show that $\mathbf{1}$ undergoes three successive one-electron oxidations at increasingly positive potentials. The first oxidation $\left(\mathrm{E}_{\mathrm{pa}}=0.64 \mathrm{~V}, \mathrm{CV}\right.$ scan rate $\left.0.2 \mathrm{~V} \mathrm{~s}^{-1}\right)$, is totally irreversible, taking place at the tertiary amine group and giving the corresponding ammonium ion $\mathbf{1 - \mathbf { H } ^ { + }}$ owing to fast $\mathrm{H}$-atom abstraction (most likely from solvent) by the putative tamoxifen radical cation $\mathbf{1}^{+\bullet}$. The subsequent oxidations at more positive potentials take place at the arylethynyl part of the molecule $\left(\mathrm{E}_{1 / 2}\right.$ values, $0.94 \mathrm{~V}$ and $\left.1.33 \mathrm{~V}\right)$. The fact that the first oxidation of tamoxifen takes place at its amine group calls into question the anodic oxidation mechanism for tamoxifen given in previous literature and provides a basis for reexamination of its anodic mechanism under aqueous electrochemical conditions.

\section{Conflict of Interest}

The authors declare that there is no conflict of interest.

\section{Acknowledgments}

We thank the National Science Foundation for support of this work under NSF-CHE1212339. 


\section{$\underline{\text { References }}$}

1. V.C. Jordan, J. Med. Chem. 46 (2003) 883.

2. M.N. Singh; H.F. Stringfellow, E. Paraskevaidis, P.L. Martin-Hirsch, F.L. Martin, Cancer Treat. Rev. 33 (2007) 91.

3. J.M.P.J. Garrido, E.M.P.J. Garrido, A.M. Oliveira-Brett, F. Borges, Curr. Drug Metab. 12 (2011) 372.

4. G.S. Wilson, in A.J. Bard, M. Stratmann (Eds), Encyclopedia of Electrochemistry, vol. 9, Bioelectrochemistry, Wiley-VCH, Weinheim, 2002.

5. C. Kohlmann, S. Lütz, in O. Hammerich, B. Speiser (Eds), Organic Electrochemistry, CRC Press, Boca Raton, $5^{\text {th }}$ Ed., 2016, pp. 1511-1541.

6. R.D. Webster, in O. Hammerich, B. Speiser (Eds), Organic Electrochemistry, CRC Press, Boca Raton, $5^{\text {th }}$ Ed., 2016, pp. 1543-1567.

7. Z. Fijalek, J. Chodkowski, M. Warowna, J. Electroanal. Chem. 226 (1987) 129.

8. J. Wang, X. Cai, J.R. Fernandes, M. Ozsoz, D. H. Grant, Talanta 45 (1997) 273.

9. X-x. Guo, Z-J. Song, X-j. Tian, J-f. Song, Anal. Lett. 41 (2008) 1225.

10. R.J. LeSuer, C. Buttolph, W.E. Geiger, Anal. Chem. 76 (2004) 6395.

11. G. Gritzner, J. Kuta, Pure Appl. Chem. 56 (1984) 461.

12. R.R. Gagne, C.A. Koval, G.C. Lisensky, Inorg. Chem. 19 (1980) 2854.

13. V.D. Parker, K. Nyberg, L. Eberson, J. Electroanal. Chem. 22 (1969) 150.

14. A.J. Bard, J. Phelps, J. Electroanal. Chem. 25 (1970) App 2.

15. J. D. Stuart, W.E. Ohnesorge, J. Am. Chem. Soc. 93 (1971) 4531.

16. U. Svanholm, B.S. Jensen, V.D. Parker, J. Chem. Soc. Perkin Trans. 2, (1974) 907.

17. J. Phelps, A.J. Bard, J. Electroanal. Chem. 68 (1976) 313.

18. B. Aalstad, V.D. Parker, J. Electroanal. Chem. 136 (1982) 251.

19. D.A. Schultz, M.A. Fox, J. Org. Chem. 55 (1990) 1047.

20. B. Rathore, S.V. Lindeman, A.S. Kumar, J.K. Kochi, J. Am. Chem. Soc. 120 (1998) 6931.

21. A. Schreivogel, J. Maurer, R. Winter, A. Baro, S. Laschat, Eur. J. Org. Chem. (2006) 3395.

22. M.G. Hill, W.M. Lamanna, K.R. Mann, Inorg. Chem. 30 (1991) 4687.

23. R.J. LeSuer, W.E. Geiger, Angew. Chem. Int. Ed. 39 (2000) 248. 
24. N. Camire, U.T. Mueller-Westerhoff, W.E. Geiger, J. Organometal. Chem. 637-639 (2001) 823.

24. W.E. Geiger, F. Barrière, Acc. Chem. Res. 43 (2010) 1030.

25. K. Lam, W.E. Geiger, J. Org. Chem. 78 (2013) 8020.

26. W.E. Geiger in A.J. Bard, C.G. Zoski (Eds) Electroanalytical Chemistry, CRC Press, 2014, Volume 25, pp 179-222.

27. A.J. Bard, L.R. Faulkner (Eds) Electrochemical Methods, John Wiley \& Sons, New York, 2001, $2^{\text {nd }}$ Ed., pp. 234-236.

28. R.N. Adams, Electrochemistry at Solid Electrodes, Marcel Dekker, New York, 1969, pp. 375-377.

29. C.K. Mann, Anal. Chem. 36 (1964) 2424.

30. O. Onumara in O. Hammerich, B. Speiser (Eds), Organic Electrochemistry, CRC Press, Boca Raton, $5^{\text {th }}$ Ed., 2016, pp 1103-1105.

31. The potentials ( $v s \mathrm{NHE}$ ) reported in reference 29 were converted to ferrocene/ferrocenium in $\mathrm{CH}_{2} \mathrm{Cl}_{2} / 0.05 \mathrm{M}\left[\mathrm{NBu}_{4}\right]\left[\mathrm{B}\left(\mathrm{C}_{6} \mathrm{~F}_{5}\right)_{4}\right]$ by subtraction of $0.55 \mathrm{~V}$.

32. In one experiment carried out with an $8.8 \mathrm{mM}$ concentration of $\mathbf{1}$, the third oxidation wave showed significant chemical reversibility. The possible role of analyte concentration on the oxidation of $\mathbf{1}$ remains an open question. In a separate experiment, we were unable to reproduce this effect over the concentration range of $0.47 \mathrm{mM}$ to $3.3 \mathrm{mM}$.

33. J. Osteryoung, J.J. O'Dea in A.J. Bard (Ed), Electroanalytical Chemistry, Marcel Dekker, 1986, Volume 14, pp. 209-308 (esp pp. 228-237).

34. R.S. Nicholson, I. Shain, Anal. Chem. 36 (1964) 706.

35. A.J. Bard, L.R. Faulkner (Eds) Electrochemical Methods, John Wiley \& Sons, New York, 2001, $2^{\text {nd }}$ Ed., pp. 496-497.

36. In order to complete the electrolysis of $8.8 \mathrm{mM} \mathrm{1}$, it was necessary to periodically rinse the $\mathrm{Pt}$ working electrode with dichloromethane, thereby removing loosely adsorbed species.

37. The potential measured for the irreversible reduction of $\mathbf{1}-\mathbf{H}^{+}$was quite dependent on the type and polishing history of working electrode that was employed. The most reproducible data was obtained at a gold electrode $\left(\mathrm{E}_{\mathrm{pc}}=-1.5 \mathrm{~V}\right)$. At $\mathrm{Pt}$, the potential varied between $-1.2 \mathrm{~V}$ and $-1.5 \mathrm{~V}$, and at glassy carbon the results were even more irreproducible.

38. In one experiment, electrolysis of $15 \mathrm{mg} 1 \mathrm{in} 7 \mathrm{~mL}$ dichlormethane yielded $20 \mathrm{mg}$ of chromatographed product.

39. ${ }^{1} \mathrm{H}$ NMR $\left(\mathrm{CDCl}_{3}\right) \delta(\mathrm{ppm})$, with emphasis on the methyl and ethynyl protons of the amino side chain : $[\mathbf{1 - H}]\left[\mathrm{B}\left(\mathrm{C}_{6} \mathrm{~F}_{5}\right)_{4}\right], 0.85(\mathrm{t}, 3 \mathrm{H}), 2.38(\mathrm{q}, 2 \mathrm{H}), \underline{2.75(\mathrm{~s}, 6 \mathrm{H})}, \underline{3.20(\mathrm{t}, 2 \mathrm{H})}, 4.02(\mathrm{t}, 2 \mathrm{H})$, 
$6.38(\mathrm{~d}, 2 \mathrm{H}), 6.77(\mathrm{~d}, 2 \mathrm{H}), 7.04(\mathrm{~m}, 3 \mathrm{H}), 7.09(\mathrm{t}, 2 \mathrm{H}), 7.18(\mathrm{~m}, 3 \mathrm{H}), 7.28(\mathrm{t}, 2 \mathrm{H})$. For $\mathbf{1}$ in $\mathrm{CDCl}_{3}$, $0.93(\mathrm{t}, 3 \mathrm{H}), \underline{2.29(\mathrm{~s}, 6 \mathrm{H})}, 2.46(\mathrm{q}, 2 \mathrm{H}), \underline{2.65(\mathrm{t}, 2 \mathrm{H})}, 3.94(\mathrm{t}, 2 \mathrm{H}), 6.57(\mathrm{~d}, 2 \mathrm{H}), 6.78(\mathrm{~d}, 2 \mathrm{H}), 7.13$ $(\mathrm{m}, 3 \mathrm{H}), 7.18(\mathrm{t}, 2 \mathrm{H}), 7.26(\mathrm{~m}, 3 \mathrm{H}), 7.35(\mathrm{t}, 2 \mathrm{H})$. Integration of appropriate resonances for $\mathbf{1}$ and $\mathbf{1 - H ^ { + }}$ confirmed that the worked-up samples contained $10-15 \%$ of the former.

40. Measured conductance of $0.65 \mathrm{mM}$ solutions in acetonitrile : $1,12 \mu \mathrm{S} ;\left[\mathrm{FeCp}_{2}\right]\left[\mathrm{B}\left(\mathrm{C}_{6} \mathrm{~F}_{5}\right)_{4}\right]$, $940 \mu \mathrm{S} ;[\mathbf{1 - H}]\left[\mathrm{B}\left(\mathrm{C}_{6} \mathrm{~F}_{5}\right)_{4}\right], 712 \mu \mathrm{S}$.

41. Elemental analysis with calculated for $[\mathbf{1 - H}]\left[\mathrm{B}\left(\mathrm{C}_{6} \mathrm{~F}_{5}\right)_{4}\right], \mathrm{C}_{50} \mathrm{H}_{30} \mathrm{BF}_{20} \mathrm{NO}: \mathrm{C}: 58.50 \%$, calc. $57.11 \% ; \mathrm{H}, 3.04 \%$, calc. $2.88 \% ; \mathrm{N}, 1.45 \%$, calc. $1.33 \%$.

42. O. Hammerich in O. Hammerich, B. Speiser (Eds), Organic Electrochemistry, CRC Press, Boca Raton, $5^{\text {th }}$ Ed., 2016, pp 571-574.

43. K. D. Moeller in Organic Electrochemistry, H.J. Schäfer (Ed), for A.J. Bard, M. Stratmann (Eds), Encyclopedia of Electrochemistry, Wiley-VCH, 2004, Volume 8, pp.280-285.

44. W. Beck, K. Sünkel, Chem. Rev. 88 (1988) 1405.

45. J.D. Stuart, W.E. Ohnesorge, The Electrochemical Society, New York N.Y., May 1969, Abstract No. 128, pp 305-307. 
Figure 1. $\mathrm{CV}$ scan of $1.0 \mathrm{mM} 1$ in $\mathrm{CH}_{2} \mathrm{Cl}_{2} / 0.1 \mathrm{M}\left[\mathrm{NBu}_{4}\right]\left[\mathrm{PF}_{6}\right]$ at ambient temperature, $0.2 \mathrm{~V} \mathrm{~s}^{-1}$, 2 mm GCE.

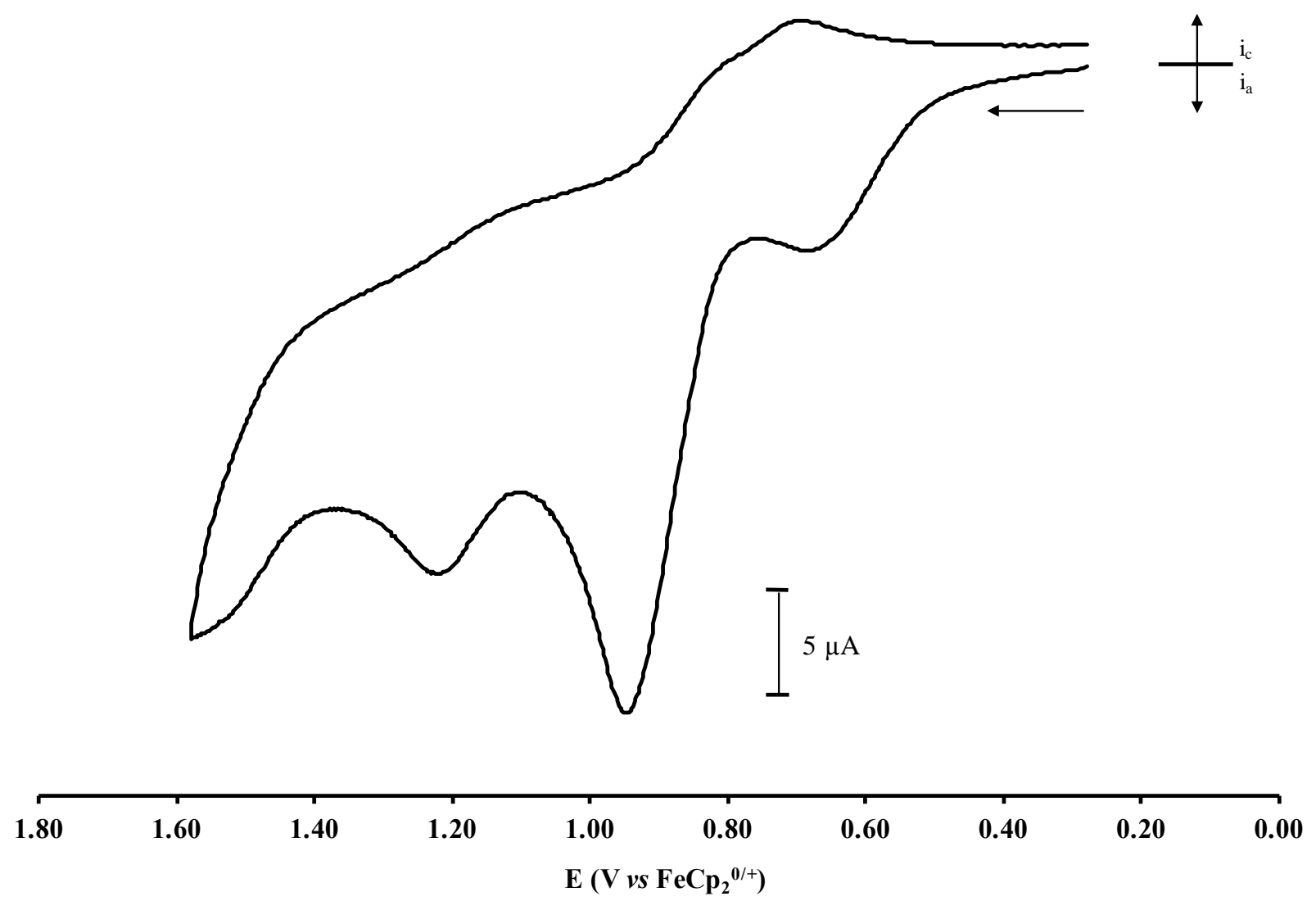


Figure 2. $\mathrm{CV}$ scans of $0.83 \mathrm{mM} 1$ in $\mathrm{CH}_{2} \mathrm{Cl}_{2} / 0.05 \mathrm{M}\left[\mathrm{NBu}_{4}\right]\left[\mathrm{B}\left(\mathrm{C}_{6} \mathrm{~F}_{5}\right)_{4}\right]$ at $298 \mathrm{~K}$ with different switching potentials, $0.2 \mathrm{~V} \mathrm{~s}^{-1}, 1 \mathrm{~mm}$ GCE. Each scan was initiated at $0 \mathrm{~V}$ and switched at either $0.8 \mathrm{~V}$ (dotted line), $1.15 \mathrm{~V}$ (dashed line), or $1.45 \mathrm{~V}$ (solid line).

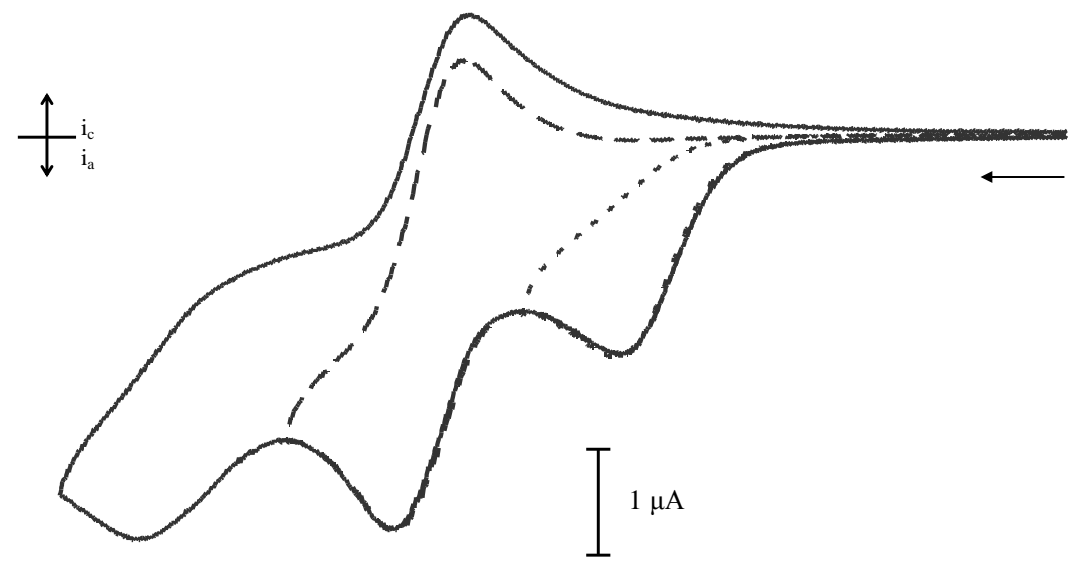

\begin{tabular}{rlllllllll}
\hline 1.60 & 1.40 & 1.20 & 1.00 & 0.80 & 0.60 & 0.40 & 0.20 & 0.00 & -0.20 \\
& & & $\mathrm{E}(\mathrm{V} v s$ & $\left.\mathrm{FeCp}_{2}{ }^{0 /+}\right)$ & & & &
\end{tabular}


Figure 3. Square wave voltammogram $(10 \mathrm{~Hz})$ of $0.83 \mathrm{mM} 1$ in $\mathrm{CH}_{2} \mathrm{Cl}_{2} / 0.05 \mathrm{M}$ $\left[\mathrm{NBu}_{4}\right]\left[\mathrm{B}\left(\mathrm{C}_{6} \mathrm{~F}_{5}\right)_{4}\right]$ at $298 \mathrm{~K}$. Pulse height $=0.05 \mathrm{~V}, 1 \mathrm{~mm} \mathrm{GCE}$.

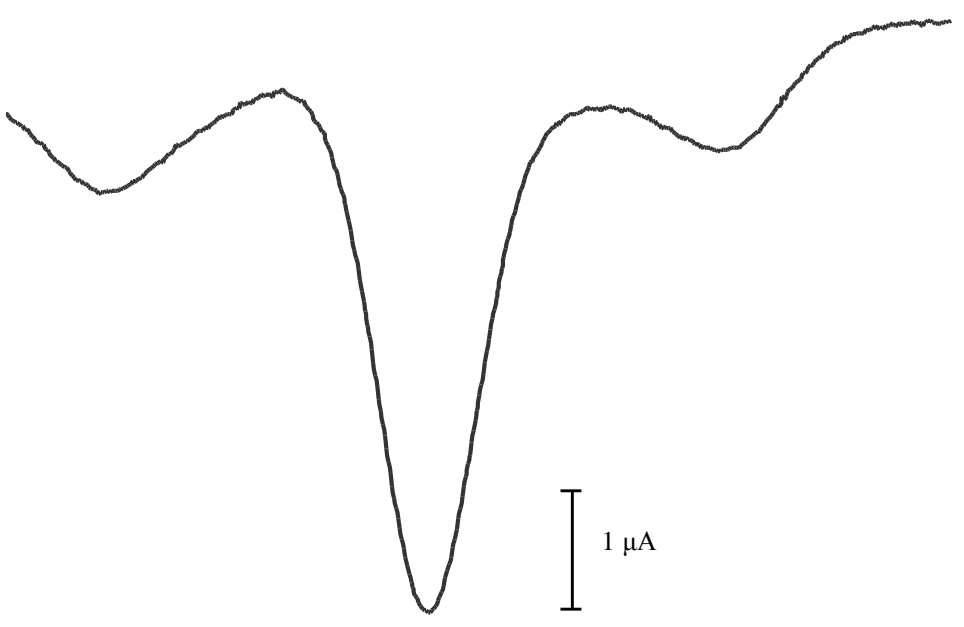

\begin{tabular}{|c|c|c|c|c|c|c|c|}
\hline 1.60 & 1.40 & 1.20 & 1.00 & 0.80 & 0.60 & 0.40 & 0.20 \\
\hline
\end{tabular}


Figure 4. CV scans $\left(0.2 \mathrm{~V} \mathrm{~s}^{-1}\right)$ at $2 \mathrm{~mm} \mathrm{GCE}$ tracking the ambient temperature bulk oxidation of $1.1 \mathrm{mM} 1$ in $\mathrm{CH}_{2} \mathrm{Cl}_{2} / 0.05 \mathrm{M}\left[\mathrm{NBu}_{4}\right]\left[\mathrm{B}\left(\mathrm{C}_{6} \mathrm{~F}_{5}\right)_{4}\right]$, followed by bulk re-reduction of its electrolysis product $\mathbf{1}-\mathbf{H}^{+}$. Dashed line: prior to bulk electrolysis; solid line: after anodic bulk electrolysis at $\mathrm{E}_{\text {appl }}=0.9 \mathrm{~V}$; dotted line: after cathodic "back-electrolysis" at $\mathrm{E}_{\text {appl }}=-1.5 \mathrm{~V}$.

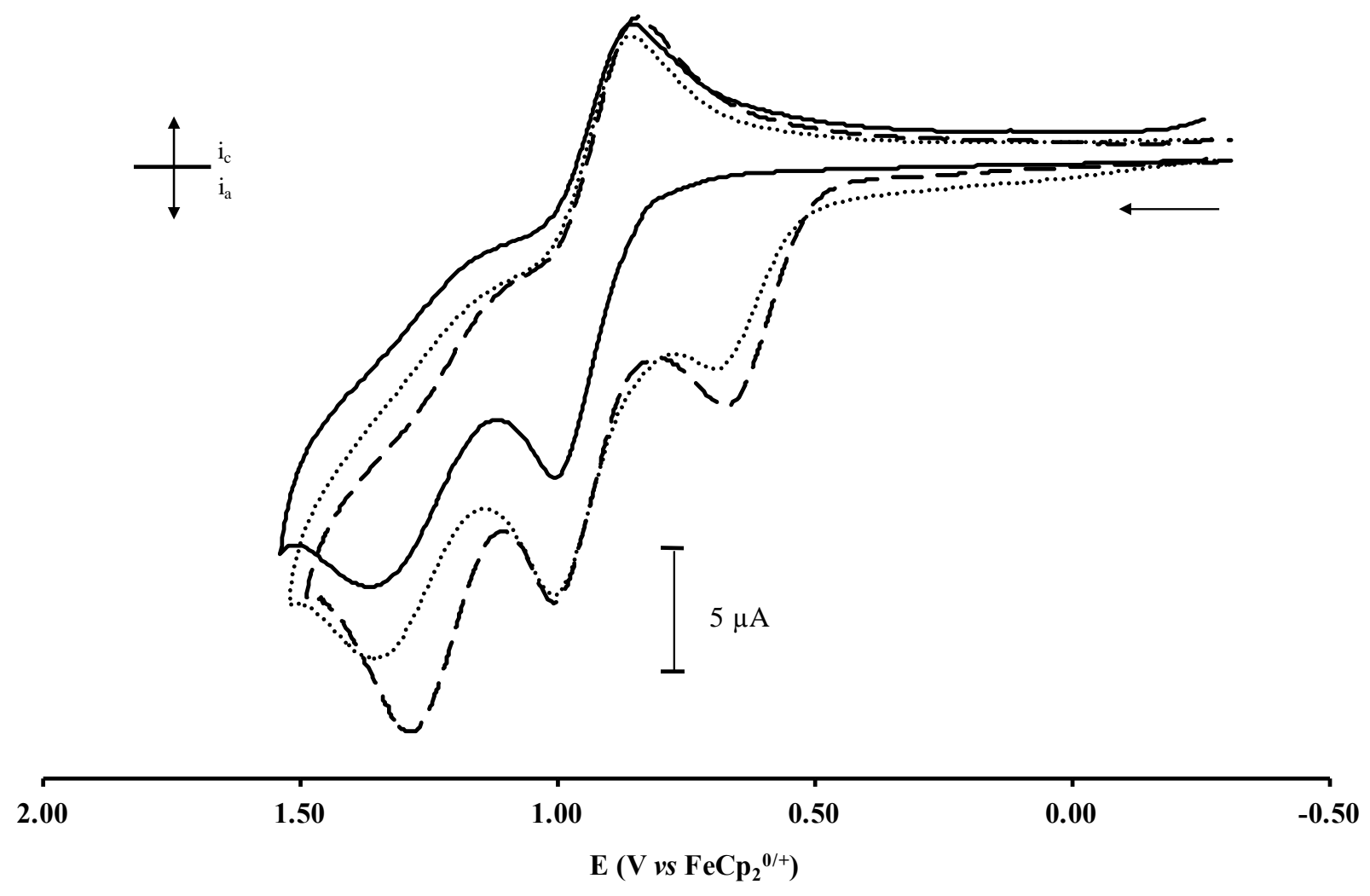


Figure 5. CV scan $\left(0.2 \mathrm{~V} \mathrm{~s}^{-1}, 2 \mathrm{~mm}\right.$ Pt electrode) of ambient temperature solution of $\mathbf{1}-\mathbf{H}^{+}$after its formation through bulk anodic oxidation of $1.3 \mathrm{mM} 1$ in $\mathrm{CH}_{2} \mathrm{Cl}_{2} / 0.05 \mathrm{M}\left[\mathrm{NBu}_{4}\right]\left[\mathrm{B}\left(\mathrm{C}_{6} \mathrm{~F}_{5}\right)_{4}\right]$.

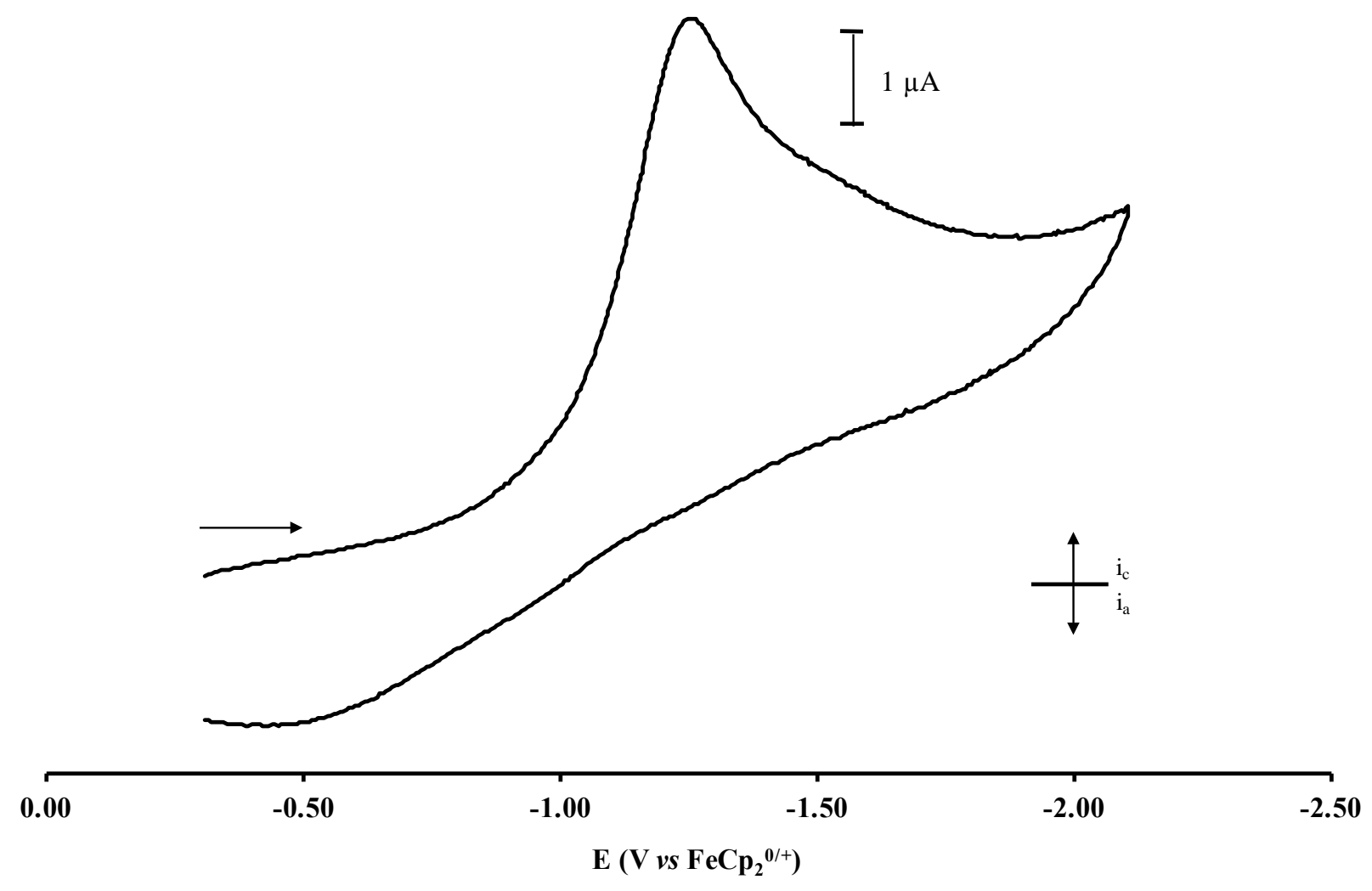




\section{$\underline{\text { Table of Contents }}$}

Nonaqueous Electrochemical Oxidation of Tamoxifen

Kan Wu, Stephen J. Van Wyck, William E. Geiger

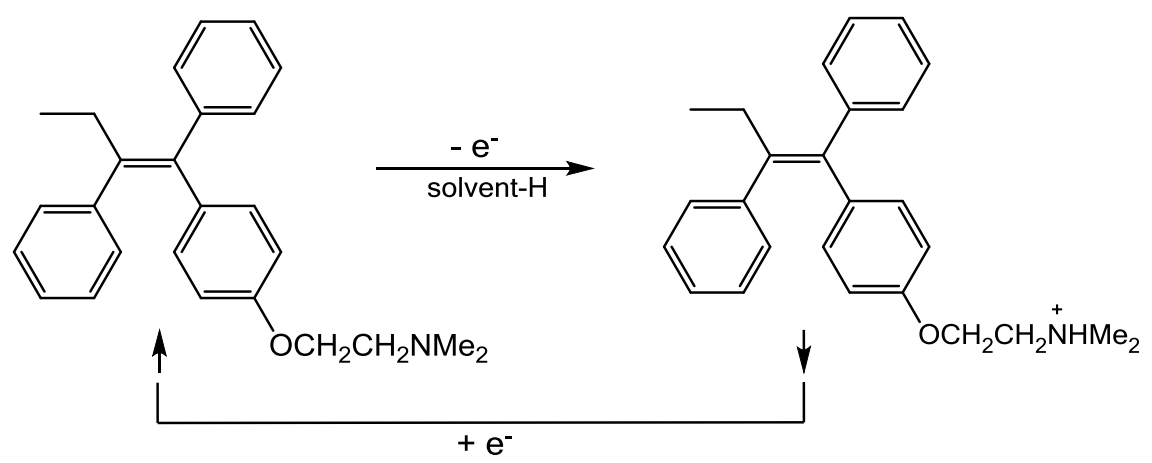

